Voix et Images

voixetimages

\title{
Bibliographie de Pierre Nepveu
}

\section{Fannie Loiselle}

Volume 34, numéro 1 (100), automne 2008

\section{Pierre Nepveu}

URI : https://id.erudit.org/iderudit/019407ar

DOI : https://doi.org/10.7202/019407ar

Aller au sommaire du numéro

\section{Éditeur(s)}

Université du Québec à Montréal

\section{ISSN}

0318-9201 (imprimé)

1705-933X (numérique)

Découvrir la revue

\section{Citer ce document}

Loiselle, F. (2008). Bibliographie de Pierre Nepveu. Voix et Images, 34(1),

91-105. https://doi.org/10.7202/019407ar d'utilisation que vous pouvez consulter en ligne.

https://apropos.erudit.org/fr/usagers/politique-dutilisation/ 


\section{B I B L I O G R A P H I E D E P IER R E NEP V E U}

$$
+++
$$

FANNIE LOISELLE

Université du Québec à Montréal

\section{I . E U V R E S}

I. 1. Pó si e

+ Voies rapides, Montréal, Hurtubise HMH, coll. «Sur parole», 1971, 112 p.

+ Épisodes, Montréal, l'Hexagone, 1977, 70 p.

+ Couleur chair, avec quatre dessins de Francine Prévost, Montréal, l'Hexagone, 1980, 92 p.

+ Mahler et autres matières. Poèmes, avec une eau-forte de Francine Labelle, Saint-Lambert et Chambly, Éditions du Noroît, coll. «L'Instant d'après», 1983, 74 p.

+ Romans-fleuves, Saint-Hippolyte, Éditions du Noroît, 1997, 93 p.

+ Lignes aériennes, Montréal, Éditions du Noroît, 2002, 112 p.

+ Le sens du soleil. Poèmes, 1969-2002, Montréal, l'Hexagone, coll. «Rétrospectives», 2005, 455 p.

\section{I . 2 . R o m a n s}

+ L'hiver de Mira Christophe, Montréal, Boréal, 1986, 218 p.

+ Des mondes peu habités, Montréal, Boréal, 1992, 192 p.

\section{3. Es s a is}

+ Les mots à l'écoute. Poésie et silence chez Fernand Ouellette, Gaston Miron et Paul-Marie Lapointe, Québec, Presses de l'Université Laval, coll. "Vie des lettres québécoises», 1979, 292 p. ; Québec, Nota bene, coll. «Visées critiques», 2002, 360 p.

+ L'écologie du réel. Mort et naissance de la littérature québécoise contemporaine, Montréal, Boréal, coll. «Papiers collés», 1988, 241 p. ; coll. «Boréal compact», 1999, 241 p.

+ Intérieurs du Nouveau Monde. Essais sur les littératures du Québec et des Amériques, Montréal, Boréal, coll. «Papiers collés», 1998, 378 p.

+ Lectures des lieux. Essais, Montréal, Boréal, coll. «Papiers collés», 2004, 270 p.

\section{4. Ant hologies}

+ La poésie québécoise, des origines à nos jours, en collaboration avec Laurent Mailhot, Québec et Montréal, Presses de l'Université du Québec et l'Hexagone, 1981, 714 p. ; Montréal, Typo, 1986, 2007, 642 p.

+ Gaston Miron, Poèmes épars, en collaboration avec Marie-Andrée Beaudet, Montréal, l'Hexagone, coll. «L'appel des mots», 2003, 124 p. 
+ Gaston Miron, Un long chemin. Proses, 1953-1996, en collaboration avec Marie-Andrée Beaudet, Montréal, l'Hexagone, 2004, 477 p.

\section{I.5. Direction $d^{\prime}$ ouvrages collectifs}

+ Montréal imaginaire. Ville et littérature, en collaboration avec Gilles Marcotte, Saint-Laurent, Fides, 1992, 424 p.

+ Au-delà de L'homme rapaillé. Poèmes épars, avec la collaboration de Marie-Andrée Beaudet et Catherine Morency, Québec, Nota bene, coll. «Séminaires», 2006, 195 p.

+ Relire Juan Garcia, en collaboration avec Isabelle Miron, Québec, Nota bene, coll. "Séminaires», 2006, $156 \mathrm{p}$.

\section{I.6. Traductions anglaises des œuvres de Pierre Nepveu}

+ Still Lives (Des mondes peu habités) par Judith Weisz Woodsworth, Winnipeg, Nuage Editor, 1997, 156 p.

+ Romans-fleuves (Romans-fleuves) par Don Winkler, Toronto, Exile Editions, 1999, 103 p.

+ Mirabel (Lignes aériennes) par Judith Cowan, Montréal, Signal Editions, 2004, 106 p.

\section{I.7. Introductions et préfaces}

+ Préface, Joël Pourbaix, Séquences initiales, Ottawa, Éditions de l'Université d'Ottawa, coll. «L'Astrolabe», 1980, 55 p.

+ Préface, Frédéric-Jacques Temple, Québec vivant. Anthologie, Marseille, Sud, coll. «Domaine étranger", 1986, p 7-14.

+ «La voix inquiète», Nicole Brossard, À tout regard, Montréal, Bibliothèque québécoise, 1989, p. 7-12.

+ Présentation, Michel Beaulieu, Fuseaux. Poèmes choisis, Saint-Hippolyte, Québec, Éditions du Noroît, coll. «Ovale», 1996, p. 9-14.

+ Présentation, Albert Lozeau, Intimité et autres poèmes, Montréal, Les Herbes rouges, coll. «Five o'clock", 1997, p. 7-16.

+ Préface, Paul-Marie Lapointe, Le vierge incendié; suivi de Nuit du 15 au 26 novembre 1948, Montréal, Typo, 1998, p. 7-16.

+ Préface, Hélène Dorion, D'argile et de souffle. Poèmes choisis, 1983-2000, Montréal, Typo, 2002, p. 7-23.

+ Préface, Poètes du Noroît. Petite anthologie de la poésie québécoise, textes choisis par Álvaro Faleiros, Montréal, Bibliothèque québécoise, 2003, p. 7-17.

+ Préface, Herménégilde Chiasson, Conversations, Sudbury, Éditions Prise de parole, coll. «Bibliothèque canadienne-française», 2006, p. 5-10.

\section{I.8. Proses et poèmes parus dans des périodiques}

+ «La force des choses», Écrits du Canada français, n 27, 1969, p. 59-97.

+ «Pièces minimales», Etudes françaises, vol. VIII, n 4, novembre 1972, p. 375-386.

+ «Scénario pour un amour définitif», Estuaire, n 7, mars 1978, p. 39-46.

+ "Data Songs», La Nouvelle Barre du jour, nº 83, 1979, p. 42.

+ "Cinq poèmes », La Nouvelle Barre du jour, no 123, février 1983, p. 170-174.

+ DESAUTELS, Denise, et Pierre NEPVEU, «Poèmes», Ellipse, n 32, 1984, p. 12-39.

+ «San Francisco», La Nouvelle Barre du jour, n 140, juin 1984, p. 99.

+ «Le retranchement», Liberté, no 173 (vol. XXIX, n 5), octobre 1987, p. 70-72. 
+ «Lettre d'adieu à Terezita de Jesús», Liberté, nos 208-209 (vol. XXXV, nºs 4-5), aoûtoctobre 1993, p. 8-17.

+ «Portrait du poète en astronaute récalcitrant», Spirale, no 168, septembre-octobre 1999, p. 28.

+ «Exercices de survie», Contre-jour, n 3, hiver 2004, p. 7-26.

+ «Maison trouble», Estuaire, no 120, automne 2004, p. 65-68.

+ «Des pierres sur la table», Jet d'encre, no 8, été, 2006, p. 45-47.

\section{I.9. Participation à des ouvrages collectifs}

+ "L'Hexagone et les Nouveaux Courants», René Dionne (dir.), Le Québécois et sa littérature, Sherbrooke, Éditions Naaman, coll. «Littératures», 1984, p. 197-214.

+ "Qu'est-ce que la transculture?», André Brochu (dir.), Autrement, le Québec. Conférences 19881989, Montréal, Département d'études françaises, Université de Montréal, 1989, p. 15-31.

+ «Les Juifs à Montréal. Le tiers inclus?», Régine Robin et al., Montréal. L'invention juive, Montréal, Université de Montréal, 1991, 109 p.

+ "Trouver son âme en Amérique», Benoît Melançon et Pierre Popovic (dir.), Montréal 16421992. Le grand passage, Montréal, XYZ éditeur, coll. «Théorie et littérature», 1994, p. 115-125.

+ «Le sujet, sa patrie, son monde. L’horizon américain», Benoît Melançon et Pierre Popovic (dir.), Saint-Denys Garneau et La Relève. Actes du colloque tenu à Montréal le 12 novembre 1993, Québec, Fides, 1995, p. 35-46.

+ «La passion du retour. Écritures italiennes au Québec», Winfried Siemerling (dir.), Writing Ethnicity. Cross-Cultural Consciousness in Canadian and Québécois Literature, Toronto, ECW Press, 1996, p. 105-115.

+ "Vers une nouvelle subjectivité ?», Bénédicte Mauguière (dir.), Cultural Identities in Canadian Literature. Identités culturelles dans la littérature canadienne, New York, Peter Lang, 1998, VIII, p. 123-129.

+ «Writing and Reading in the Year 2000 : A Survey of Quebec's Mindscape», Ines Molinaro et Christopher Rolfe (dir.), Focus on Quebec 2. Further Essays on Quebecois Society \& Culture, Edinburgh and Leceister, British Association for Canadian Studies and Centre for Quebec Studies, 2000, p. 1-14.

+ «Figures du paysage dans la poésie québécoise actuelle», Michael Bishop et Christopher Elson (dir.), Contemporary French Poetics, Amsterdam and New York, Rodopi, 2002, p. 19-29.

+ «Le petit Farouest de Jacques Ferron», Brigitte Faivre-Duboz et Patrick Poirier (dir.), Jacques Ferron. Le palimpseste infini, Outremont, Lanctôt éditeur, coll. "Cahiers Jacques Ferron», 2002, p. 23-47.

+ «Gaston Miron: l'atelier du poète», Marc-André Bernier (dir.), Archive et poétique de l'invention, Québec, Nota bene, 2003, p. 237-253.

+ «La fin des illuminations», Catherine Morency (dir.), La littérature par elle-même, Québec, Nota bene, 2005, p. 65-72.

+ "vice Versa ou la déstabilisation des lettres québécoises», Anna Paola Mossetto (dir.), avec la collaboration de Jean-François Plamondon, Le projet transculturel de vice Versa, Bologne (Italie), Pendragon, 2006, p. 81-95.

+ "Gaston Miron: fragments d'un récit de soi», Jean-Pierre Bertrand et François Hébert (dir.), L'universel Miron, Québec, Nota bene, coll. «Convergences», 2007, p. 113-127.

+ "Archives de l'autre, archives de soi», Jacinthe Martel (dir.), Archives littéraires et manuscrits d'écrivains. Politiques et usages du patrimoine, Québec, Nota bene, coll. «Convergences, 2008, p. 271-282. 


\section{10. Critique littéraire et articles}

\section{10.1 . O u vrage}

+ La poésie immédiate. Lectures critiques 1985-2005, Québec, Nota bene, coll. «Nouveaux Essais Spirale», 2008, 265 p. $^{1}$

\section{10.2. Études et comptes rendus critiques}

+ "Le bonheur, d'Agnès Varda», Le Sainte-Marie, 5 octobre 1965, p. 12.

+ "Gilbert Langevin, l'énergumène», Études françaises, vol. IX, n 4, novembre 1973, p. 337-344.

+ "La poétique de Gilbert Langevin», Livres et auteurs québécois, 1973, p. 312-324.

+ «Le poème inachevé», Études françaises, vol. XI, no 1, février 1975, p. 55-65.

+ «Le grotesque dans La Guerre, yes Sir!», Nord, n 6, automne 1976, p. 49-59.

+ «Les nouvelles voix en poésie. Sens interdit», Lettres québécoises, n 3, septembre 1976, p. 11-13.

+ «Michel Lemaire. L'envers des choses», Lettres québécoises, n 5, février 1977, p. 13-15.

+ «La jeune poésie, la critique peut-être...», Lettres québécoises, n 6, avril-mai 1977, p. 13-15.

+ «La poésie et quelques questions», Liberté, no 111 (vol. XIX, nº 3), mai-juin 1977, p. 87-91.

+ "Note provisoire sur les Euvres créatrices complètes », Lettres québécoises, n 7 », aoûtseptembre 1977, p. 17-18.

+ «Alexis Lefrançois : les mots éblouis de silence», Lettres québécoises, n 8, novembre 1977, p. 15-16.

+ «Herménégilde Chiasson: Rapport sur l'état de mes illusions », Livres et auteurs québécois, 1977, p. 151-152.

+ «VLB (commentaires)», La Nouvelle Barre du Jour, n 63, février 1978, p. 89.

+ «Le poème: du fait divers à l'événement», Lettres québécoises, n 3, avril 1978, p. 16-18.

+ «Les Herbes rouges... jusqu'à François Charron», Lettres québécoises, nº 11, septembre 1978, p. $38-40$.

+ "L'Autre et la Sorcière: Madeleine Gagnon et Francine Déry ", Lettres québécoises, n 12 , novembre 1978, p. 15-16.

+ "Gilbert Langevin. Mon refuge est un volcan", Livres et auteurs québécois, 1978, p. 134-136.

+ "Philippe Haeck: une poétique de la naïveté», Lettres québécoises, no 13, février 1979, p. 22-24.

+ [Sans titre], Lettres québécoises, no 14, avril-mai 1979, p. 22-25 [Comptes rendus de Conduite intérieure de Jean Charlebois, Sol inapparent de Gilles Cyr, Peinture aveugle de Robert Melançon et De temps en temps de Jean-Yves Théberge].

+ «Quelques réflexions sur la critique et la poésie», Lettres québécoises, nº 15, aoûtseptembre 1979, p. 25-26.

+ «Philippe Haeck, Naissances. De l'écriture québécoise», Livres et auteurs québécois, 1979, p. 213-215.

+ «Du corps et de quelques poètes », Lettres québécoises, no 16, hiver 1979-1980, p. 21-23.

+ «La tombée du temps», Études françaises, vol. XVI, n² 2, avril 1980, p. 47-63.

+ "Les années soixante-dix: du commencement à la fin», Lettres québécoises, n 17, printemps 1980, p. 26-29.

+ «La poésie entre le nouveau et l'ancien», Lettres québécoises, no 18, été 1980, p. 27-29.

+ «François Charron, l'urgence de l'écriture (entrevue)», Lettres québécoises, n 18, été 1980, p. $40-48$.

$$
+++
$$

1 Les chroniques reprises dans cet ouvrage sont signalées ici par un astérisque en marge. 
+ «De l'“importance" de la littérature», Lettres québécoises, n 19, automne 1980, p. 28-31.

+ "Le Romancier fictif. Essai sur la représentation de l'écrivain dans le roman québécois d'André Belleau ", Voix et Images, vol. VI, n 1, automne 1980, p. 147-149.

+ "Nicole Brossard et France Théoret: la pensée/l'impensable», Lettres québécoises, nº 20, hiver 1980-1981, p. 24-27.

+ «L'écriture à la première personne: Vanier et Beausoleil», Lettres québécoises, n 21, printemps 1981, p. 26-28.

+ «Petites misères du masculin singulier», Lettres québécoises, n² 22, été 1981, p. 29-31.

+ «Feu la modernité ?», Lettres québécoises, n 23, automne 1981, p. 30-33.

+ «Haeck et Charron : travailler à ne pas s'appartenir», Lettres québécoises, nº 25, printemps 1982, p. 36-39.

+ "Abel, Steven et la souveraine poésie», Études françaises, vol. XIX, nº 1, printemps 1983, p. 27-40.

+ «A (Hi)story That Refuses the Telling: Poetry and the Novel in Contemporary Québécois Literature », traduction anglaise par Karen McPherson, Yale French Studies, vol. LXV, 1983, p. 90-105.

+ «La prose du poème», Études françaises, vol. XX, n 3, hiver 1984, p. 15-27.

+ «BJ/NBJ : difficile modernité», Voix et Images, vol. X, nº 2, hiver 1985, p. 159-165.

* + «Poèmes d'amour, chants de mort», Spirale, n 50, mars 1985, p. 5.

+ «L'essentiel et le frivole», Spirale, n 52, mai 1985, p. 6.

+ «Les matières du réel», Spirale, n 53, juin 1985, p. 6.

+ «Lire comme un roman», Spirale, n 54, septembre 1985, p. 5.

+ «Voyages dans le non-sens», Spirale, n 54 , septembre 1985, p. 9.

* + «Quelques voyages dans le réel», Spirale, n 56, novembre 1985, p. 3.

+ «Mouvement et immobilité», Spirale, n 57, décembre 1985, p. 7.

+ «Poèmes d'air ou de matière», Spirale, n 59, mars 1986, p. 3-4.

+ «Diversité, actualité», Spirale, nº 60, avril 1986, p. 14.

+ «La machine-écriture, illimitée», Spirale, n 60, avril 1986, p. 16.

+ «L'existence en danger», Liberté, n 164 (vol. XXVIII, n²), avril 1986, p. 51-58.

* + «Écrire la douleur», Spirale, nº 62, été 1986, p. 8.

* + «Il n'y a pas de fin du monde», Spirale, n 63, septembre 1986, p. 3.

* + «Poèmes de Suède en noir et blanc», Spirale, nº 64, octobre 1986, p. 9.

* + «Nouveau lyrisme?», Spirale, n 65, novembre 1986, p. 6.

* + «Penser la disparition [d'un être aimé]», Spirale, nº 66, décembre 1986, p. 10-11.

* + «L'aménagement du monde», Spirale, nº 68, mars 1987, p. 13.

+ «Tourist room», Spirale, n 69 , avril 1987, p. 7.

+ «Tout l'horizon du vivant», Spirale, nº 71, été 1987, p. 7.

+ «La poésie contemporaine au Québec: la chasse au réel », Écrits du Canada français, nº 61, 1987, p. 101-117.

* + «Hypothèses sur l'existence», Spirale, nº 85, février 1989, p. 10.

+ «La loi des formes», Liberté, nº 181 (vol. XXXI, n 1), février 1989, p. 13-19.

* + «Passion flamande et thé japonais», Spirale, no 87, avril 1989, p. 11.

+ «Sur la piste de la beauté», Spirale, no 88, mai 1989, p. 16.

+ «Variations sur des thèmes connus », Spirale, n 92, novembre 1989, p. 9.

+ «Supplément à l'histoire d'une épidémie», Écrits du Canada français, nº 70, 1990, p. 117-124. 
+ "A Woman With No Special Qualities», Ellipse, n 43, 1990, p. 9-15.

* + «De Manhattan à la mer des Antilles», Spirale, no 94, février 1990, p. 11.

+ «Leçon sur la méthode», Spirale, n 98, été 1990, p. 5.

+ «Le poème québécois de l'Amérique», Études françaises, vol. XXVI, n² 2, automne 1990, p. 9-19.

+ «L'obscène et le métaphysique», Voix et Images, vol. XVI, n 3, printemps 1991, p. 393-401.

"Entretiens dans Charlevoix», Voix et Images, vol. XVI, n 3, printemps 1991, p. 535-539.

+ «Paul-Marie Lapointe et la question de l'Amérique», Voix et Images, vol. XVII, n 3 , printemps 1992, p. 435-445.

* + «Poète sans domicile connu », Spirale, n 117, septembre 1992, p. 5.

* + «Les langues d'Abraham Moses Klein», Spirale, n 118, octobre 1992, p. 9.

+ «Un amour impossible à dire», Spirale, no 120, décembre 1992-janvier 1993, p. 8.

+ «Le lyrisme d'une génération perdue», Spirale, n 122, mars 1993, p. 4.

+ «L'Europe comme un pèlerinage», Spirale, n 123, avril 1993, p. 7.

+ «Écrire pour sauver son âme», Spirale, no 124, mai 1993, p. 13.

+ "Au pays de Monsieur Crèvecoeur», Spirale, n 127, octobre 1993, p. 3.

* + «Il n'y a pas de pays sans paysans», Spirale, n 128, novembre 1993, p. 16.

+ «Le noir et le rouge. Mythes et réalités d'un continent», Spirale, n 129, décembre 1993janvier 1994, p. 9.

+ [Sans titre], Recherches sociographiques, vol. XXXV, nº 1, janvier-avril 1994, p. 128-130.

+ «L'appel des mots. Lecture de St-Denys Garneau. Poèmes pour un monde dépeuplé»; "Revue gaz moutarde 1992-1993", Spirale, nº 130, février 1994, p. 8-10.

* + «Éloge de la mesure», Spirale, no 136, octobre 1994, p. 5.

+ «Une icône et quelques incendies», Spirale, n 136, octobre 1994, p. 7.

* + «Turbulences aux confins du moi», Spirale, no 138, décembre 1994-janvier 1995, p. 3-4.

+ «Les mirages de l'ethnicité», Spirale, n 139 , février 1995, p. 3-4.

+ «Le sentier qui rétrécissait», Spirale, nº 143, juin-juillet-août 1995, p. 20.

+ «Vivement Montréal!», Études françaises, vol. XXXI, n², automne 1995, p. 95-103.

+ «Roman d'un continent problématique», Spirale, n 144, septembre-octobre 1995, p. 11.

+ «Richesses du paradigme américain», Spirale, no 144, septembre-octobre 1995, p. 32.

+ «Le nouvel âge ou la fin des inquiétudes", Spirale, nº 145, novembre-décembre 1995, p. 13.

+ «Gaston Miron. Le temps de la métamorphose», Le Devoir, 21-22 septembre 1996, p. A5.

+ «Suzanne Jacob: poèmes de la femme piégée», Voix et Images, vol. XXI, nº 2, hiver 1996, p. 243-249.

* + «La longue marche d'un Acadien errant», Spirale, nº 146, janvier-février 1996, p. 3-4.

+ «Le nihiliste et le dandy», Spirale, n 148, mai-juin 1996, p. 27.

+ "Amours, délices et autres sucreries», Spirale, no 149, juillet-août 1996, p. 9.

+ «Éloge de la modération», Spirale, n 150, septembre-octobre 1996, p. 7.

+ «Les montagnes, la plaine, la vie», Spirale, n 151, novembre-décembre 1996, p. 4-5.

+ "L'écriture souveraine, malgré tout», Spirale, n 151, novembre-décembre 1996, p. 8-9.

+ «Une ville en poésie», Ellipse, n 56, 1996, p. 9-27 (traduction anglaise, p. 61-78).

+ "L'intimité aux quatre vents: pratique de la forme brève chez Gilbert Langevin », Voix et Images, vol. XXII, nº 3, printemps 1997, p. 473-482.

+ «Gaston Miron, l'ouvreur du pays, 1928-1996», en collaboration avec Jean-François Nadeau et Michaël La Chance, Spirale, no 153, mars-avril 1997, p. 3-4.

+ «Le siècle de l'histoire et de quelques erreurs», Spirale, n 153, mars-avril 1997, p. 15. 
+ «Un site poétique à fréquenter», Spirale, n 154, mai-juin 1997, p. 3.

* + «Le règne des loups et des hyperboles», Spirale, n 154, mai-juin 1997, p. 36.

+ «La folle loi de la jungle», Spirale, no 156, septembre-octobre 1997, p. 3.

+ «Des Tropiques à l'Arctique: mutations de l'imaginaire», Spirale, nº 156, septembre-octobre 1997, p. 10.

+ «La mise en images d'un grand roman», Spirale, nº 157, novembre-décembre 1997, p. 26.

+ «Promenade guidée en quartier yiddish», Spirale, n 160, mai-juin 1998, p. 4.

+ «Repli ethnique et passage des frontières», Spirale, n 160, mai-juin 1998, p. 5.

+ «Voyage en mémoire terre-neuvienne», Spirale, n 161, juillet-août 1998, p. 21.

* + «La solitude du promeneur de fond», Spirale, n 161, juillet-août 1998, p. 7.

+ «Chaleur de la conscience», Spirale, n 162, septembre-octobre 1998, p. 17.

+ «L'homme qui faisait mine de ne rien voir», Les Écrits, no 97, décembre 1999, p. 145-154

[Discours de réception à l'Académie des lettres du Québec].

+ «Jean-Aubert Loranger. Contours de la conscience», Voix et Images, vol. XXIV, n 2, hiver 1999, p. 277-288.

+ «Accueillir l'étranger ou le circonscrire», Spirale, n 164, janvier-février 1999, p. 21.

+ «Cosmogonie d'un touriste ordinaire», Spirale, n 164, janvier-février 1999, p. 28.

+ «Paysage de la poésie québécoise en 1999», Poésie 99, printemps 1999, p. 57-60.

+ «La force fragile d'un pays incertain», Spirale, n 165, mars-avril 1999, p. 4-5.

* «Du côté de la vie, malgré tout», Spirale, n 166, mai-juin 1999, p. 16.

+ «Le jeune homme et la mort», Spirale, no 166, mai-juin 1999, p. 20.

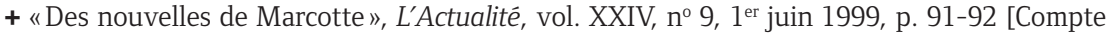
rendu de La mort de Maurice Duplessis de G. Marcotte].

* + «Symphonie de la gloire et de la grandeur», Spirale, no 167, juillet-août 1999, p. 11.

+ «Héloïse au jour le jour», Spirale, nº 167, juillet-août 1999, p. 21.

* + «Rythmes d'une existence à Moncton», Spirale, nº 174, septembre-octobre 2000, p. 20.

+ "Cioran ou la maladie de l'éternité », Études françaises, vol. XXXVII, nº 1, 2001, p. 11-21.

+ «Désordre et vacuité : figures de la judéité québécoise-française», Études françaises, vol. XXXVII, n³, 2001, p. 69-84.

+ «Les écritures migrantes à l'âge de la critique», Spirale, nº 186, septembre-octobre 2002, p. 40-41.

+ «Sur la piste du western et du country», Spirale, n 187 , novembre-décembre 2002, p. 5-6.

+ «Un thêâtre des discours: du poème en prose à l'époque de l'Hexagone», Études françaises, vol. XXXIX, n³, automne 2003, p. 47-60.

+ «Un long voyage jusqu'au Pacifique», Spirale, n 193, novembre-décembre 2003, p. 12-13.

+ «Ici, sur la batture: voyage au pays de Pierre Morency», Autre Sud (France), n 23, décembre 2003, p. 16-24.

+ «Roland Giguère ou le principe du grain de sable», Liberté, nº 265 (vol. XLVI, n 3), septembre 2004, p. 44-49.

+ «Retour au Québec», Cités, n 23, 2005/3, p. 217-220.

* + «Écrire et aimer dans le désastre», Spirale, no 205, novembre-décembre 2005, p. 12-13.

+ «A Little Toil of Love. L'Amérique and Quebec's Emily Dickinson», introduction et traduction de David Palmieri, The Emily Dickinson Journal (États-Unis), vol. XV, nº 1, Johns Hopkins University Press, 2006, p. 1-15. 


\section{10.3. Direction d'un numéro de revue}

+ En collaboration avec Benoît Melançon, «VLB», Études françaises, vol. XIX, nº 1, printemps 1983, p. 5-89.

\section{10.4. Articles d'opinion}

+ «Les nouveaux écrivains et la critique (5). Les risques», Le Devoir, 12 mai 1979, p. 24.

+ «Recension de L'Arpenteur et le Navigateur dans la revue La Tribune juive», Le Devoir, 26 avril 1997, p. A11.

+ «L'impossible oubli», Le Devoir, 10 juin 1997, p. A9.

+ «Une bureaucratie en folie», Le Devoir, 23 avril 1999, p. A10.

+ «Le Farouest de Jacques Ferron», Le Devoir, 2 octobre 2000, p. B7.

+ «Lettres. Un silence éloquent», Le Devoir, 24 septembre 2004, p. A8.

+ «Incurie bureaucratique», La Presse, 29 novembre 2004, p. A13.

+ «Libre opinion. Culture politique et politique de l'inculture», Le Devoir, 23 janvier 2006, p. A6.

+ "L'autre bout de la lorgnette», Le Devoir, 21 novembre 2006, p. A7.

+ «Raisons et déraisons de l'Histoire», Le Devoir, 13 avril 2007, p. A8.

+ «Bouchard et Taylor au pays des grandes gueules», Le Devoir, 7 septembre 2007, p. A9.

+ «Les manques d'une critique. Réponse à Étienne Beaulieu », Spirale, n 222, septembre-octobre 2008, p. 42.

\section{11. Document sonore}

+ Michel Beaulieu, Poèmes choisis, Montréal, Éditions du Noroît, 1995, 1 cassette.

\section{12 . Entretiens}

+ FOURNIER, Danielle, «Entrevue de Pierre Nepveu», Mobius, n²5, été 1985, p. 3-11.

+ GILBERT, Bernard, «Poésie québécoise: portrait récent (entretien avec Pierre Nepveu et Normand de Bellefeuille)", Nuit blanche, n 28, mai-juin 1987, p. 10-15.

+ JUBINVILLE, Yves, "Vol au-dessus de nos lettres», Continuum, Université de Montréal, semaine du 9 janvier 1989, p. 15.

+ YOKEN, Mel B., «Pierre Nepveu», Entretiens québécois, Montréal, Éditions Pierre Tisseyre, 1989, p. 235-253.

+ ROYER, Jean, «Entretien avec Pierre Nepveu», dans Poètes québécois. Entretiens, Montréal, l'Hexagone, coll. «Typo », 1991, p. 198-212 (d'abord paru dans Estuaire, n 31, printemps 1984, p. 70-72).

+ MAROTTE, Sylvain (réal.), Pierre Nepveu: poète [enregistrement vidéo], La Prairie, Téridan, 2005, 1 vidéodisque (24 min).

+ BORDELEAU, Francine, «Pierre Nepveu : écrire pour aménager le réel», Lettres québécoises, $\mathrm{n}^{\circ} 117$, printemps 2005, p. 8-10.

\section{I. PRIX E T D IS TINCTIONS}

+ Prix Québec-Paris, en 1981, pour La poésie québécoise, des origines à nos jours.

+ Prix Victor-Barbeau de l'Académie des lettres du Québec, en 1988, pour L'écologie du réel.

+ Prix Canada-Suisse, en 1993, pour L'écologie du réel.

+ Prix Gabrielle-Roy de l'Association des littératures canadiennes et québécoises, en 1993, pour Montréal imaginaire. 
+ Prix du Gouverneur général du Canada, en 1997, pour Romans-fleuves.

+ Prix du Gouverneur général du Canada, en 1998, pour Intérieurs du Nouveau Monde.

+ Prix de la critique littéraire Jean-Éthier Blais, en 1999, pour Intérieurs du Nouveau Monde.

+ Prix du Gouverneur général du Canada, en 2003, pour Lignes aériennes.

+ Grand Prix du Festival international de la Poésie, en 2003, pour Lignes aériennes.

+ Prix Athanase-David, en 2005.

\section{RÉCEPTION CRITIQUE ET ÉTUDES}

III.1. Sur l'auteur et son œuvre en général

+ [ANONYME], «Pierre Nepveu», Réginald Hamel, John Hare et Paul Wyczynski (dir.), Dictionnaire des auteurs de langue française en Amérique du Nord, Montréal, Fides, 1989, p. 1027-1028.

+ [ANONYME], «Pierre Nepveu», M.-A. Guérin, en collaboration avec Réginald Hamel, Dictionnaire Guérin des poètes d'ici. De 1606 à nos jours, Montréal, Guérin, [2001] 2005, p. 1028.

+ AGUIAR, Flavio, «Noir sur blanc. Présentation de trois poètes québécois : Saint-Denys Garneau, Gaston Miron et Pierre Nepveu", Études littéraires, vol. XVI, n² 2, août 1983, p. 203-222.

+ BROCHU, André, «Pierre Nepveu, écrivain d'Amérique», Lettres québécoises, n 117, printemps 2005, p. 7-12.

+ BROCHU, André, «Pierre Nepveu, l'existeur», Les Écrits, n 93, 1998, p. 41-54 (d'abord paru, dans une traduction anglaise de D. G. Jones, sous le titre: «Pierre Nepveu, the Existor», Ellipse, no 59, printemps 1998, p. 13-22).

+ CHARTRAND, Robert, «Le lecteur de lieux», Le Devoir, 12 novembre 2005, p. G8.

+ CÔTÉ, Lucie, «Sur les traces de Pierre Nepveu», La Presse, 5 octobre 2003, p. F3.

+ GAUVIN, Lise, et Gaston MIRON, «Pierre Nepveu», Écrivains contemporains du Québec, Montréal, l'Hexagone, 1989, p. 405-406.

+ HAREL, Simon, Les passages obligés de l'écriture migrante, Montréal, XYZ éditeur, 2005, p. 1570.

+ KOUCHNER, Martin, «Les disciples de Rabelais», Le Devoir, 10-11 janvier 2004, p. G19.

+ LAFERRIÈRE, Dany, «Je lis nu dans ma baignoire», La Presse, 7 mai 2006, p. A15.

+ LEMAIRE, Michel, «Pierre Nepveu dans la poésie québécoise contemporaine», Dalhousie French Studies, vol. VII, automne-hiver 1984, p. 47-65.

+ MALENFANT, Paul Chanel, «Pierre Nepveu: la poésie sous haute tension», Le Devoir, 31 décembre 2005, p. E1.

+ PALMIERI, David, "Emily Dickinson de Saint-Hyacinthe: La poétesse américaine au Québec», Québec Studies, vol. XXXII, automne 2001-hiver 2002, p. 119-127.

+ SIMON, Sherry, "Culture and Its Values: Critical Revisionism in Quebec in the 1980s», Robert Lecker (dir.), Canadian Canons : Essays in Literary Value, Toronto, University of Toronto Press, 1991, p. 167-179.

\section{III.2. Sur des ouvrages particuliers}

\section{III.2.1 Voies rapides}

+ [ANONYME], «Voies rapides», Le Livre canadien, vol. II, n 224, 1971, p. 1.

+ AGUIAR, Flavio, "Voies rapides", Maurice Lemire (dir.), Dictionnaire des œuvres littéraires du Québec, Tome V, Montréal, Fides, 1978, p. 950-951.

+ BEAUliEU, Michel, «Voies rapides», Point de mire, vol. III, n 5, 13 novembre 1971, p. 38.

+ GERVAIS, Marielle, «Voies rapides», Livres et auteurs québécois, 1971, p. 142-144. 
+ MAJOR, J[ean]-L[ouis], «Poésie», University of Toronto Quarterly, vol. XLI, nº 4, Summer 1972, p. 348.

+ MARCOTTE, Gilles, "Chroniques. La poésie - pour l'âme», Études françaises, vol. VIII, nº 1, février 1972, p. 99-100.

+ PARADIS, Suzanne, «Racine, Nepveu et Gignac. L'occulte présence de Rimbaud», Le Soleil, 11 décembre 1971, p. 58.

+ PILON, Jean-Guy, «Poésie. Pierre Nepveu et Guy Désilets», Le Devoir, 15 février 1972, p. 13.

+ POULIN, Gabrielle, "Voies rapides et Épisodes de Pierre Nepveu, poète du macadam», Relations, vol. XXXVII, nº 428, juillet-août 1977, p. 222-223.

\section{I . 2.2. Épisodes}

+ [ANONYME], «Pierre Nepveu», Lettres québécoises, n 8, novembre 1977, p. 36.

+ BAYARD, Caroline, "Poésie», University of Toronto Quarterly, vol. L, nº 4, été 1981, p. 41-54.

+ BEAULIEU, Michel, "Un raz-de-marée poétique», Le Livre d'ici, vol. II, n²7, 13 avril 1977, p. 1 [reproduit dans Progrès-dimanche, 8 mai 1977, p. 62].

+ BEAUSOLEIL, Claude, «Lire aujourd'hui. Poétique(ment)», Hobo/Québec, avril-juin 1977, p. 27.

+ GIGUÈRE, Richard, «Poésie», University of Toronto Quarterly, vol. LVII, n 4, été 1978, p. 357366.

+ GIRARD, Michel, «Notre choix. Épisodes de Pierre Nepveu», Nos livres, novembre 1977, p. 5-7.

+ HÉBERT, François, «Lefrançois, Beaulieu, Nepveu, Vanier», Liberté, no 114 (vol. XIX, nº 6), novembre-décembre 1977, p. 93-99.

+ LEMAIRE, Michel, «Épisodes de Pierre Nepveu», Le Droit, 21 mai 1977, p. 20.

+ MELANÇON, Robert, "Pierre Nepveu, Épisodes», Livres et auteurs québécois, 1977, p. 133-134.

+ PONTBRIAND, Jean-Noël, «Épisodes et Couleur chair», Gilles Dorion (dir.), Dictionnaire des œuvres littéraires du Québec, Tome VI, Montréal, Fides, 1994, p. 30.

+ POULIN, Gabrielle, «Voies rapides et Épisodes de Pierre Nepveu, poète du macadam», Relations, vol. XXXVII, n 428, juillet-août 1977, p. 222-223.

+ RENAUD, Jacques, «Qui a peur d'un alexandrin?», Le Devoir, 4 juin 1977, p. 16.

\section{III.2.3. Les mots à l'écoute. Poésie et silence chez Fernand} Ouellette, Gaston Miron et Paul-Marie Lapointe

+ [ANONYME], «Les mots à l'écoute», Lettres québécoises, n 14, avril 1979, p. 21.

+ [ANONYME], «Pierre Nepveu», La Nouvelle Barre du jour, nº 123, février 1983, p. 227.

+ BINET, Jean-Léonard, «Courtepointes», Le Livre d'ici, vol. IV, nº 39, 4 juillet 1979.

+ CARASSUS, Émilien, "Les mots à l'écoute. Poésie et silence chez Fernand Ouellette, Gaston Miron et Paul-Marie Lapointe", Études canadiennes/Canadian Studies, n 11 , décembre 1981, p. 183-184.

+ CHAMBERLAND, Roger, "Les mots à l'écoute», Québec français, décembre 1979, p. 10.

+ CLOUTIER, Cécile, «Pierre Nepveu, Les mots à l'écoute», University of Toronto Quarterly, vol. XLIX, nº 4, été 1980, p. 475-476.

+ DUMONT, François, "Les mots à l'écoute», Gilles Dorion (dir.), Dictionnaire des œuvres littéraires du Québec, Tome VI, Montréal, Fides, 1994, p. 551-553.

+ FISETTE, Jean, «Pierre Nepveu, Les mots à l'écoute», Livres et auteurs québécois, 1979, p. 243245. 
+ GALLAYS, François, «Les mots à l'écoute de Pierre Nepveu », Lettres québécoises, n 16, hiver 1979-1980, p. 68.

+ GALLAYS, François, «Essai de critique littéraire: de 1961 à 1980 », Paul Wyczynski, François Gallays et Sylvain Simard (dir.), Archives des lettres canadiennes, T. VI, Montréal, Fides, 1985, p. 109-141.

+ GIGUÈRE, Richard, «En écoutant», Canadian Literature, no 86, automne 1980, p. 106-108.

+ LEMAIRE, Michel, «Pierre Nepveu: Les mots à l'écoute», Voix et Images, vol. V, n 2, hiver 1980, p. 407-409.

+ ROYER, Jean, «D'un plaisir à l'autre: le silence de la poésie», Le Devoir, 19 mai 1979, p. 23.

\section{III.2.4. Couleur chair}

+ AQUIN, Pierre-Stéphane, "Couleur chair. Pierre Nepveu», Le Bulletin Pantoute, septembrenovembre 1980, p. 6.

+ BEAULIEU, Michel, «Pierre Nepveu. Une poésie englobante et pénétrante», Le Livre d'ici, vol. V, no 44, 6 août 1980, p. 2.

+ BOUCHARD, Christian, «Pierre Nepveu, Couleur chair», Estuaire, n² 20, été 1981, p. 122-123.

+ BROCHU, André, «Rétrospectives et prospectives», Voix et Images, vol. VII, n 3, printemps 1982, p. 583-590.

+ FADIN, Max, «Pierre Nepveu. Couleur chair», Livres et auteurs québécois, 1980, p. 124-126.

+ GALLAYS, François, "Couleur chair de Pierre Nepveu», Lettres québécoises, n 20, 1980-1981, p. 98.

+ PONTBRIAND, Jean-Noël, «Épisodes et Couleur chair», Gilles Dorion (dir.), Dictionnaire des œuvres littéraires du Québec, T. VI, Montréal, Fides, 1994, p. 30.

+ ROYER, Jean, «Trois compagnons pathétiques», Le Devoir, 20 septembre 1980, p. 23.

\section{III.2.5. La poésie québécoise, des origines à nos jours}

+ BEAUliEU, Ivanhoé, "Restituer les pouvoirs de la poésie québécoise», La Presse, 6 juin 1981, p. C2.

+ BLAIS, Jacques, "La poésie québécoise des origines à nos jours de Mailhot-Nepveu», Lettres québécoises, nº 23, automne 1981, p. 42-44.

+ BOSQUET, Alain, «La poésie du Québec», Magazine littéraire, nº 179, décembre 1981, p. 75.

+ CHAMBERLAND, Roger, et André GAULIN, «La poésie québécoise des origines à nos jours », Québec français, n 43, octobre 1981, p. 18.

+ FISETTE, Jean, «Les objets du trésor... », Voix et Images, vol. VII, n 2, hiver 1982, p. 413-416.

+ GIGUĖRE, Richard, «La poésie québécoise, des origines à nos jours. Anthologie de Laurent Mailhot et Pierre Nepveu ", Estuaire, n²3, printemps 1982, p. 113-116.

+ ROYER, Jean, «Pour choisir la poésie: des anthologies», Le Devoir, 13 décembre 1986, p. C6.

+ MONTPETIT, Caroline, «Donner des ailes aux mots», Le Devoir, 24 novembre 2007, p. F1.

+ LALONDE, Étienne, «La poésie québécoise, des origines à nos jours. Compilation par Laurent Mailhot et Pierre Nepveu», Spirale, nº 222, septembre-octobre 2008, p. 41.

\section{III.2.6. Mahler et autres matières}

+ BAYARD, Caroline, «L'autotélisme est d'hier, le Nouveau lyrisme est d'aujourd'hui», University of Toronto Quarterly, vol. LIII, nº 4, été 1984, p. 360-372.

+ BEAUSOLEIL, Claude, «Gérald Godin : les mots vécus», Le Devoir, 19 novembre 1983, p. 20. 
+ BEAUSOLEIL, Claude, "Mahler et autres matières », Nos livres, vol. XV, mars 1984, p. 30-31.

+ BEAUSOLEIL, Claude, «La mesure des mots», Les livres parlent, Trois-Rivières, Écrits des forges, 1984, p. 178-179.

+ BROCHU, André, "Flamboyants et profonds", Voix et Images, vol. IX, n 3, printemps 1984, p. 155-164 [reproduit dans Tableau du poème, Montréal, XYZ éditeur, 1994, p. 77-78].

+ CHAMBERLAND, Roger, "Mahler et autres matières », Aurélien Boivin (dir.), Dictionnaire des œuvres littéraires du Québec, Tome VII, Montréal, Fides, 2003, p. 564-565.

+ CLOUTIER, Guy, «Où c'est ailleurs?», Nuit blanche, octobre-novembre 1984, p. 4.

+ CORRIVEAU, Hugues, "Couleur mauve, Couleur chair», Spirale, n 39, décembre 1983, p. 14.

+ GAUDET, Gérald, "Mahler et autres matières», Estuaire, n 31, printemps 1984, p. 70-72.

+ GIROUX, Robert, "Mahler et autres matières », Mœbius, nº 21, printemps 1984, p. 70-72.

+ GIROUX, Robert, «Les voix de Montréal», Canadian Literature, printemps 1985, p. 126-128.

+ ISSENHUTH, Jean-Pierre, «Malgré Mahler», Liberté, no 172 (vol. XXIX, n 4), août 1987, p. 81-83.

+ LEMAIRE, Michel, «L'émotion d'un lyrisme neutre», Lettres québécoises, n 33, printemps 1984, p. 56-57.

+ MALENFANT, Paul Chanel, «Mahler et autres matières », Nuit blanche, décembre 1983janvier 1984, p. 13-14.

+ M[ELANÇON], R[obert], «Le chant de la terre», Liberté, nº 151 (vol. XXVI, nº 1), février 1984, p. 94.

\section{III.2.7. L'hiver de Mira Christophe}

+ AAS-ROUXPARIS, Nicole, «La thématique de l'hiver dans L'hiver de Mira Christophe de Pierre Nepveu», The French Review (États-Unis), vol. LXVI, nº 1, 1992, p. 89-97.

+ AAS-ROUXPARIS, Nicole, «Une conque abandonnée: Mira Christophe dans L'hiver de Mira Christophe de Pierre Nepveu », Dalhousie French Studies, vol. XXII, printemps-été 1992, p. 5362.

+ AUDET, Noël, «De la poésie à la prose», Lettres québécoises, n 44, hiver 1986-1987, p. 26-28.

+ BEAUDOIN, Réjean, «La ville toute verte, bordée de montagnes enneigées», Liberté, n 170 (vol. XXIX, n²), avril 1987, p. 118-124.

+ CLOUTIER, Guy, «Une date dans l'histoire du roman québécois», Le Soleil, 27 septembre 1986, p. F9.

+ DÉCARIE, Isabelle, «Penser le transnationalisme. Une lecture de L'hiver de Mira Christophe de Pierre Nepveu ", Globe. Revue internationale d'études québécoises, vol. III, nº 1, 2000, p. 125136.

+ GIRARD, Jean-Pierre, «La fiction qui disperse la pluie», Lettres québécoises, n 69, printemps 1993, p. 15-16.

+ GOBIN, Pierre, «Montréal et Vancouver, métro-pôles d'un univers : L'hiver de Mira Christophe de Pierre Nepveu», Tangence, no 48, octobre 1995, p. 10-23.

+ LÉPINE, Stéphane, "Pour une pratique raisonnée du désastre», Le Devoir, 11 octobre 1986, p. C3.

+ MARCOTTE, Gilles, «La beauté de Mira Christophe», L'Actualité, vol. XI, nº 12, décembre 1986, p. 163.

+ MICHON, Jacques, «Couples», Voix et Images, vol. XIII, n 1, automne 1987, p. 189-192.

+ OUELLET, R., «Un perpétuel frôlement du désastre: L'hiver de Mira Christophe par Pierre Nepveu», Francofonia (Italie), nº 16, 1989, p. 3-15. 
+ SAINT-MARTIN, Lori, «Les nuits de Vancouver», Spirale, n 65, novembre 1986, p. 9.

+ WHITFIELD, Agnès, "Silences du corps: L'hiver de Mira Christophe de Pierre Nepveu ", Voix et Images, vol. XVIII, $\mathrm{n}^{\circ}$ 1, automne 1992, p. 52-61.

\section{III.2.8. L'écologie du réel. Mort et naissance de la littérature québécoise contemporaine}

+ BASILE, Jean, «Mort et exil: un point de vue de Pierre Nepveu sur la littérature québécoise», La Presse, 28 janvier 1989, p. K3.

+ BEAUDOIN, Réjean et Robert MELANÇON, «Chronique d'une mort différée», nº 183 (vol. XXXI, nº 3), juin 1989, p. 138-143.

+ BIRON, Michel, «Dépayser la littérature québécoise», Spirale, n 100, octobre 1990, p. 5.

+ BISHOP, Neil B., "L'écologie du réel: mort et naissance de la littérature québécoise contemporaine», University of Toronto Quarterly, vol. LIX, nº 1, automne 1989, p. 213-216.

+ CLÉMENT, Anne-Marie, Robert DION et Frances FORTIER, «L'architecte du lisible. Lecture de L'écologie du réel de Pierre Nepveu», Tangence, n 51, mai 1996, p. 123-143.

+ FERLAND, Guy, «Réflexions sur l'étrangeté de la littérature québécoise», Le Devoir, 18 février 1989, p. D1.

+ HORGUELIN, Thierry, «Le conflit insoluble de la modernitée, Spirale, n 87, avril 1989, p. 8.

+ IMBERT, Patrick, "L'écologie du réel by Pierre Nepveu», Canadian Literature, no 129, été 1991, p. 225-226.

+ MAJOR, Robert, «Papiers collés, papiers à lire», Voix et Images, vol. XIV, nº 3, printemps 1989, p. 498-503.

+ WHITFIELD, Agnès, «Pour une littérature post-québécoise», Lettres québécoises, n 53 , printemps 1989, p. 45-46.

\section{III.2.9. Des mondes peu habités}

+ [ANONYME], «Still Lives», Canadian Book Review Annual, 1998, p. 191.

+ [ANONYME], «Still Lives», Prairie Fire, vol. XIX, n 4, décembre-mars 1998, p. 154-155.

+ BEAUDOIN, Réjean, "Un homme diminué», Liberté, nºs 208-209 (vol. XXXV, nºs 4-5), aoûtoctobre 1993, p. 265-269.

+ BIRON, Michel, «Sens du rituel», Voix et Images, vol. XVIII, n 2, hiver 1993, p. 400-403.

+ CÔTÉ, Lucie, «Dans la solitude de la ville de Pierre Nepveu», La Presse, 27 septembre 1992, p. B7.

+ DÉCARIE, Nicole, "Compte rendu du livre Des mondes peu habités de P. Nepveu», Mœbius, nos 54-55, automne 1992, p. 202-203.

+ FORTIN, Marie-Claude, "Des mondes peu habités - Pouvoir intime», Voir, vol. VI, nº 43, 24 septembre 1992, p. 30.

+ GIRARD, Jean-Pierre, "Compte rendu du livre Des mondes peu habités de P. Nepveu », Lettres québécoises, nº9, printemps 1993, p. 15-17.

+ GIRARD, Marie-Claire, «Pierre Nepveu. La mélancolie d'une génération», Le Devoir, 26 septembre 1992, p. D1.

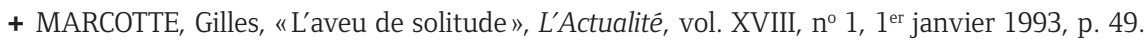

+ MARTEL, Réginald, «Un dramatique retour au monde», La Presse, 4 octobre 1992, p. B5.

+ VOISARD, Anne-Marie, «Des mondes peu habités de Pierre Nepveu», nº, 3 octobre 1992, p. F13. 


\section{III.2.10. Montréal imaginaire. Ville et littérature}

+ DENIS, Jean-Pierre, "Compte rendu du livre Montréal imaginaire. Ville et littérature sous la direction de P. Nepveu et G. Marcotte», Spirale, nº 118, octobre 1992, p. 7-10.

\section{I I . 2 . 1 1. Romans-fleuves}

+ CANTIN, David, «Vivre dans la présence du temps», Le Devoir, 10 mai 1997, p. D6.

+ CLÉMENT, Anne-Marie, "Paul Chanel Malenfant, Fleuves; Pierre Nepveu, Romans-fleuves», Tangence, n 57 , mai 1998, p. 123-128.

+ CORRIVEAU, Hugues, "Si c'est un livre c'est un espace pour durer», Lettres québécoises, n 88, hiver 1997, p. 38-39.

+ LEMAIRE, Michel, «Le fleuve et la mort», Voix et Images, vol. XXIII, n 3, printemps 1998, p. 607-612.

\section{III.2.12. Intérieurs du Nouveau Monde. Essais sur les littératures du Québec et des Amériques}

+ CHARTRAND, Robert, «L'Amérique est-elle imaginable?», Le Devoir, 28 février 1998, p. D3.

+ GAULIN, Michel, «Compte rendu du livre Intérieurs du Nouveau Monde. Essais sur les littératures du Québec et des Amériques de P. Nepveu », Lettres québécoises, n 93, printemps 1999, p. 42-43.

+ MAILHOT, Laurent, «Événements : de la poésie québécoise», Voix et Images, vol. XXIV, nº 2, hiver 1999, p. 247-263.

+ MAJOR, Robert, «L'invitation au voyage», Voix et Images, vol. XXIII, n 3, printemps 1998, p. 583-590.

+ MARCOTTE, Gilles, "Compte rendu du livre Intérieurs du Nouveau Monde. Essais sur les littératures du Québec et des Amériques de P. Nepveu », L'Actualité, vol. XXIII, n 8, 15 mai 1998, p. 97-98.

+ PATERSON, Janet M., «Intérieurs du Nouveau Monde. Essais sur les littératures du Québec et des Amériques », University of Toronto Quarterly, vol. LXI, n 1, hiver 1999, p. 429.

\section{I I 2.13. Lignes aériennes}

+ BEAUSOLEIL, Claude, «Retour à Mirabel», La Presse, 17 novembre 2002, p. F6.

+ BISSONNETTE, Thierry, «Lignes aériennes», Nuit blanche, n 90, printemps 2003, p. 18.

+ BOURGEAULT, Jean-François, "Le monument des futurs passés», Contre-jour, n 1 , printemps 2003, p. 137-142.

+ CANTIN, David, «Rester libre», Le Devoir, 31 août 2002, p. D4.

+ EPSTEIN, Ronald Charles, «Mirabel», Canadian Book Review Annual, 2005, p. 226.

+ PAQUIN, Éric, «Lignes aériennes. Grand dérangement», Voir, vol. XVII, nº 48, 27 novembre 2003, p. 26.

+ PARÉ, François, "Arpenter le territoire de l'envol», Spirale, no 191, juillet-août 2003, p. 16-17.

+ SOLWAY, David, «Translation Attains Flight» [sur Mirabel], Books in Canada, vol. XXXIV, nº 1, janvier-février 2005, p. 26.

\section{III.2.14. Gaston Miron, Poèmes épars}

+ BROCHU, André, «De paille et de tonnerre», Le Devoir, 3 mai 2003, p. F1.

+ LAFERRIĒRE, Dany, «Miron, ce compagnon de voyage», La Presse, 18 mai 2003, p. E1. 
+ MALAVOY-RACINE, Tristan, "Gaston Miron. La démarche à l'amour», Voir, vol. XVII, nº 19, 15 mai 2003, p. 30.

+ MONTPETIT, Caroline, "L'Hexagone publiera des inédits de Gaston Miron », Le Devoir, 28 janvier 2003, p. B8.

+ PARÉ, François, «Écrire comme un seul homme», Voix et Images, vol. XXXII, n² 2, hiver 2007, p. 125-128.

+ ROYER, Jean, «Gaston Miron. L’homme sans fin», La Presse, 27 avril 2003, p. F1.

\section{III.2.15. Lectures des lieux. Essais}

+ AUDET, René, «Tectonique essayiste: raconter le lieu dans l'essai contemporain», Études littéraires, vol. XXXVII, nº 1, automne 2005, p. 119-131.

+ FERRARO, Alessandra, "Compte rendu du livre Lectures des lieux de P. Nepveu», Spirale, $\mathrm{n}^{\circ}$ 202, mai-juin 2005, p. 36.

+ MONTPETIT, Caroline, "Pierre Nepveu - Terres de passage», Le Devoir, 24 avril 2004, p. F1.

+ PAQUIN, Éric, «Lectures des lieux - Lieux dits», Voir, vol. XVIII, no 33, 19 août 2004, p. 20.

III.2.16. Gaston Miron, Un long chemin. Proses, 1953-1996

+ BEAUSOLEIL, Claude, «Souverain Miron», La Presse, 9 janvier 2005, p. 4.

+ LAURIN, Danielle, «La voix de Miron», Le Soleil, 6 février 2005, p. C1.

+ MARCOTTE, Gilles, «Des mythes revus et corrigés», L'Actualité, vol. XXX, nº 4, 15 mars 2005, p. 73.

\section{III.2.17. Le sens du soleil. Poèmes, 1969-2002}

+ BROCHU, André, "Fils déchus et autres matières", Voix et Images, vol. XXXI, n 2, hiver 2006, p. $159-164$.

+ CORRIVEAU, Hugues, "Compte rendu du livre Le sens du soleil. Poèmes, 1969-2002 de P. Nepveu ", Lettres québécoises, nº 122, été 2006, p. 33.

+ JUTRAS, Benoit, «Pierre Nepveu - Garder le feu», Voir, vol. XIX, nº 50, 15 décembre 2005, p. 16.

+ LAMBERT, Vincent Charles, "Compte rendu du livre Le sens du soleil. Poèmes, 1969-2002 de P. Nepveu ", Québec français, no 141, printemps 2006, p. 10-11.

\section{I I. 3. Thè s es et $\mathrm{m}$ émoir es}

+ DROLET, Alexandre, «Phénoménologie de l'événement dans Lignes aériennes de Pierre Nepveu ", mémoire de maîtrise, Québec, Université Laval, 2008, 115 f.

+ LEWIS, Alfred Daniel, «Pierre Nepveu, Transculturalism and Neo-Quebecois Texts», mémoire de maîtrise, Sherbrooke, Université de Sherbrooke, 2002, 105 f. 